\title{
Effect of radiotherapy on coronary arteries and heart in breast-conserving surgery: a dosimetric analysis
}

\author{
Gulsen Pinar Soydemir Gocer, Elif Eda Ozer
}

Department of Radiation Oncology, Bakırköy Dr. Sadi Konuk Education and Research Hospital, Istanbul, Turkey

Radiol Oncol 2020; 54(1): 128-134.

Received 04 December 2019

Accepted 15 February 2020

Correspondence to: Dr. Gulsen Pinar Soydemir, Department of Radiation Oncology, Bakırköy Dr. Sadi Konuk Education and Research Hospital Tevfik Saglam Cd. No: 11 Bakirkoy 34158, Istanbul, Turkey. Phone: +90 53365402 26; E-mail: gulpin3528@hotmail.com

Disclosure: No potential conflicts of interest were disclosed.

Background. There are certain risks of radiotherapy (RT), especially patients with left-sided breast cancer have a higher tendency to develop cardiac complications than the right-sided cancers. This study aims to perform a dosimetric analysis the effect of RT on coronary arteries and heart in breast-conserving surgery.

Patients and methods. A total of 40 patients with early stage right and left-sided breast carcinomas (T1/T2 + NO) were randomly selected. RT was delivered to the entire breast, and tumor beds were boosted in these patients using tangential fields with computed tomography based planning. The doses for Left anterior descending coronary artery (LAD), left circumflex coronary artery (LCX), right ventricle (RV), left ventricle (LV), and heart were recorded and median values compared between groups.

Results. The highest mean of radiation dose in patients with left-sided breast cancer was to LAD $2402.48 \pm 838.39$ CGy, while the highest mean dose in right-sided breast cancer patients was to RV $130.18 \pm 24.92$. The highest maximum dose of radiotherapy was applied to heart at left-sided breast cancer patients as well as at right-sides prients. The mean $\mathrm{V} 5$ of the $\mathrm{LV}$ was $18.68 \%(6.89-31.69)$, mean $\mathrm{V} 25$ of the $\mathrm{L} V$ was $5.22 \%(0.45-16.54)$, mean $\mathrm{V} 5$ in bilateral ventricles was $23.73 \%(2.56-26.89)$, and mean V25 in bilateral ventricles $6.78 \%$ (0.63-13.63).

Conclusions. Especially in left-sided breast cancer, the most direct and best strategy to reduce and protect radiation-induced cardiac injury is to balance dose constraints between several high-dose regions of cardiac substructures and the mean heart dose.

Key words: breast cancer; radiation therapy; heart; coronary arteries

\section{Introduction}

Breast cancer is the most common cancer in women (excluding skin cancers) and is the second most common cause of death due to cancer. ${ }^{1}$ The average risk of developing breast cancer in women is $12 \%$. Age is the most important risk factor for breast cancer development. In addition, gender, a previous history of breast cancer or benign breast diseases, family history, race, menstrual history (early menarche and late menopause), first gestational age, no history of breastfeeding, alcohol consumption, diet rich in fat and calories, use of oral contraceptives, and postmenopausal hormone replacement therapy are the other risk factors for the occurrence of breast cancer.

Surgery is the main treatment modality. While surgery is performed in the early stage, locally advanced cases are operated after neoadjuvant chemotherapy. Surgery is performed as mastectomy (radical mastectomy, modified radical mastectomy, or total mastectomy) or breast-sparing surgery (wide excision, quadrantectomy, or lumpectomy). Adjuvant radiotherapy (RT) is administered to all the patients who underwent breast-sparing surgical therapy for breast cancer and those with 4 or more positive lymph nodes who underwent mastectomy. ${ }^{2}$ 
Long-term survival-related toxicities have become important to be studied, as longer-term survival rates have been achieved by the improvements in diagnosis and treatment of breast cancers. $\mathrm{RT}$ reduces the local recurrence rate of breast can$\mathrm{cer}^{3}$, however, it is not clear that the survival advantage offered in addition to surgical treatment is not related to systemic therapy. Studies have shown the survival benefit in high-risk patients with RT. ${ }^{4}$ However, there are certain risks of RT, such as skin reactions, cosmetic problems, edema in the upper extremity, pneumonia, and the cardiac toxicity, especially important in left-sided breast RT. In particular, the left anterior descending coronary artery (LAD) receives significant radiation, being in or near the target volume. ${ }^{5,6}$ Moreover, patients with left-sided breast cancer have a higher tendency to develop cardiac complications than the right-sided ones. ${ }^{7}$ In this study, we aimed to determine the RT doses to the LAD, left circumflex coronary artery $(\mathrm{LCx})$, right ventricle (RV), left ventricle (LV), and heart in patients who underwent right and leftsided breast conservative surgery and determine whether these doses constituted a risk for ischemic heart disease.

\section{Patients and methods}

This study was conducted with an approval from the Ethics Committee at the Health Sciences University, Dr. Sadi Konuk Education and Research Hospital (2018-254), ethically in accordance with the World Medical Association Declaration of Helsinki.

A total of 40 patients with early stage right and left-sided breast carcinomas (T1/T2 + N0, according to 8th edition of American Joint Committee on Cancer staging, 2017) were randomly selected, from January 2017 to December 2018. Patient contouring was performed by two independent radiation specialists. RT was delivered to the entire breast and tumor beds were boosted in these patients using tangential fields with computed tomography (CT) based planning. Patients' age, tumor localization, stage, chemotherapy protocol and number, RT dose, and the doses for LAD, LCx, $\mathrm{RV}, \mathrm{LV}$, and heart were recorded.

We based on the handbook and quantec to dose limits for critical organs in our clinic. Handbook recommendation for breast $\mathrm{RT}$ is as follows: LV and combined bilateral ventricle limits: V5 $\leq 10 \%$ and V25 $\leq 5 \%$. Contralateral breast Dmax $\leq 3 \%$, ipsilateral lung V30<15\%, contralateral lung V5 <
$15 \%$, heart V $5<5 \%$ for R-sided tumors, and $<40 \%$ for L-sided tumors.

\section{Treatment}

Forty patients who underwent RT for right and left-sided breast cancers at the Radiation Oncology Department were included in the study. All patients underwent breast-conserving surgery. Patients were usually treated in supine positions with customized immobilization device. As a part of radiation planning, contrast-enhanced CT scans were obtained in 3-mm slices. During simulation, each patient was immobilized, with the ipsilateral arm above her head. Radiopaque catheters were placed to delineate the breast areas and incision scar on the CT scan. Each patient's CT data was transferred to an in-house 3-dimensional treatment planning system. The clinical target volumes (CTVs) were contoured and reviewed by two radiation oncologists.

The whole breast was considered as the CTV. The opposite breast, heart, LAD, LCx, RV, and LV were contoured. For RT planning, two tangential beams were used with matched posterior border to avoid divergence. Physical wedges of $15^{\circ}-30^{\circ}$ were used. Only whole breast irradiation plans were included for plan comparison in this study. The total dose prescribed was $60 \mathrm{~Gy}$, with 2.0 Gy per fraction per day (50 Gy in 2 Gy/fraction to whole breast, 10 Gy in $2 \mathrm{~Gy} / 5$ fractions to tumor bed). The aim of the treatment plan was to achieve at least $95 \%$ of the planning target volume receiving 47.5 Gy (95\% of $50.0 \mathrm{~Gy})$, and the ipsilateral lung volume receiving $20 \mathrm{~Gy}$ or more (V20) 10\%, while keeping the contralateral lung below a mean dose of $5 \mathrm{~Gy}$. In all the patients, the breast was treated with 6-MV photon beam. Boost was applied with electron energy. Electron energy was selected to allow the $85-90 \%$ isodose line to encompass the target. Dose volume histograms (DVH) were reviewed for all the patients. Maximum, minimum, and mean doses (Dmax, Dmin, and Dmean) to heart, LAD, LCx, RV, and LV were calculated from the cumulative DVH.

\section{Statistical analysis}

The analyses were performed with the NCSS 11 (Number Cruncher Statistical System, 2017, Statistical Software) Program and MedCalc Statistical Software version 18 (MedCalc Software bvba, Ostend, Belgium; http://www.medcalc.org; 
TABLE 1. Patients' characteristics

\begin{tabular}{|c|c|c|c|}
\hline & & $\begin{array}{l}\text { Right-sided } \\
\text { breast cancer } \\
\mathbf{n}(\%)\end{array}$ & $\begin{array}{c}\text { Left-sided } \\
\text { breast cancer } \\
\text { n (\%) }\end{array}$ \\
\hline \multicolumn{2}{|c|}{ Breast conservation surgery } & 20 (100\%) & 20 (100\%) \\
\hline \multicolumn{2}{|c|}{ Age } & $\begin{array}{c}57.33 \pm 10.21 \\
(40-80)\end{array}$ & $\begin{array}{c}61.35 \pm 9.91 \\
(42-76)\end{array}$ \\
\hline \multirow{2}{*}{ T stage } & $\mathrm{Tl}$ & $15(75 \%)$ & $12(60 \%)$ \\
\hline & $\mathrm{T} 2$ & $5(25 \%)$ & $8(40 \%)$ \\
\hline$N$ stage & NO & $20(100 \%)$ & 20 (100\%) \\
\hline M stage & MO & 20 (100\%) & $20(100 \%)$ \\
\hline \multirow{2}{*}{ Tumor location } & inner quadrant & $6(30 \%)$ & $10(50 \%)$ \\
\hline & outer quadrant & 14 (70\%) & $10(50 \%)$ \\
\hline \multirow{2}{*}{ Tumor size } & $\leq 2 \mathrm{~cm}$ & $15(75 \%)$ & $12(60 \%)$ \\
\hline & $2-5 \mathrm{~cm}$ & $5(25 \%)$ & $8(40 \%)$ \\
\hline \multirow{2}{*}{ Chemotherapy } & Yes & $7(35 \%)$ & $11(55 \%)$ \\
\hline & No & $13(65 \%)$ & $9(45 \%)$ \\
\hline \multirow{2}{*}{$\begin{array}{c}\text { Number of } \\
\text { chemotherapy } \\
\text { cycles }\end{array}$} & 4 & $4(20 \%)$ & $6(30 \%)$ \\
\hline & 6 & $3(15 \%)$ & $5(25 \%)$ \\
\hline
\end{tabular}

TABLE 2. The dosimetric parameters of left anterior descending coronary artery (LAD), left circumflex coronary artery (LCX), right ventricle (RV), left ventricle (LV) and heart depending on the side of the tumor

\begin{tabular}{|c|c|c|c|c|}
\hline \multicolumn{2}{|c|}{$\begin{array}{l}\text { Dosimetric } \\
\text { parameters }\end{array}$} & \multirow{2}{*}{$\begin{array}{c}\begin{array}{c}\text { Right-sided breast } \\
\text { cancer }\end{array} \\
97.57 \pm 10.26 \\
(73.8-114)\end{array}$} & \multirow{2}{*}{$\begin{array}{c}\text { Left-sided breast } \\
\text { cancer }\end{array}$} & \multirow{2}{*}{$\begin{array}{l}P \text { value } \\
<0.0001\end{array}$} \\
\hline \multirow{3}{*}{ LAD } & $D_{\text {mean }}$ & & & \\
\hline & $D_{\max }$ & $\begin{array}{c}111.87 \pm 16.15 \\
(78.8-145)\end{array}$ & $\begin{array}{c}4752.83 \pm 498.46 \\
(3700-5703.8)\end{array}$ & $<0.0001$ \\
\hline & $D_{\min }$ & $\begin{array}{l}83.12 \pm 9.31 \\
(63.7-100.1)\end{array}$ & $\begin{array}{c}222.59 \pm 76.42 \\
(95-471)\end{array}$ & $<0.0001$ \\
\hline \multirow{3}{*}{ LCx } & $D_{\text {mean }}$ & $\begin{array}{l}84.99 \pm 9.09 \\
(63.8-100.8)\end{array}$ & $\begin{array}{c}170.55 \pm 45.36 \\
(85.8-260.2)\end{array}$ & $<0.0001$ \\
\hline & $D_{\text {max }}$ & $\begin{array}{c}96.27 \pm 11.33 \\
(75.6-116.3)\end{array}$ & $\begin{array}{c}203.49 \pm 55.9 \\
(112-353.9)\end{array}$ & $<0.0001$ \\
\hline & $\mathrm{D}_{\min }$ & $\begin{array}{c}74.59 \pm 8.57 \\
(54.5-92.1)\end{array}$ & $\begin{array}{c}137.63 \pm 38.59 \\
(69.7-235.5)\end{array}$ & $<0.0001$ \\
\hline \multirow{3}{*}{ RV } & $D_{\text {mean }}$ & $\begin{array}{c}130.18 \pm 24.92 \\
(110.8-224.2)\end{array}$ & $\begin{array}{c}563.65 \pm 221.78 \\
(140.9-875.6)\end{array}$ & $<0.0001$ \\
\hline & $D_{\text {max }}$ & $\begin{array}{c}464.76 \pm 517.55 \\
(221.2-2619)\end{array}$ & $\begin{array}{c}4576.55 \pm 1077.66 \\
(460.1-6149.3)\end{array}$ & $<0.0001$ \\
\hline & $D_{\min }$ & $\begin{array}{c}75.51 \pm 7.81 \\
(58.8-90.5)\end{array}$ & $\begin{array}{c}103.41 \pm 28.67 \\
(49.3-184.9)\end{array}$ & $<0.0001$ \\
\hline \multirow{3}{*}{ LV } & $D_{\text {mean }}$ & $\begin{array}{l}81.71 \pm 7.9 \\
(60.9-96.5)\end{array}$ & $\begin{array}{c}536.8 \pm 193.24 \\
(230-1018.1)\end{array}$ & $<0.0001$ \\
\hline & $D_{\text {max }}$ & $\begin{array}{c}149.13 \pm 43.75 \\
(85.1-264.2)\end{array}$ & $\begin{array}{c}4822.6 \pm 362.4 \\
(3964.4-5835.4)\end{array}$ & $<0.0001$ \\
\hline & $D_{\min }$ & $\begin{array}{c}65.75 \pm 7.02 \\
(47.1-80.2)\end{array}$ & $\begin{array}{c}105.49 \pm 26.64 \\
(52.2-184.2)\end{array}$ & $<0.0001$ \\
\hline \multirow{2}{*}{ Heart } & $D_{\text {mean }}$ & $\begin{array}{c}120.33 \pm 19.05 \\
(97.3-189.2)\end{array}$ & $\begin{array}{c}396.56 \pm 131.73 \\
(158.5-588.7)\end{array}$ & $<0.0001$ \\
\hline & $D_{\text {max }}$ & $\begin{array}{c}634.48 \pm 751.55 \\
(277-3759.5)\end{array}$ & $\begin{array}{c}5032.44 \pm 331.02 \\
(4134.3-5992.9)\end{array}$ & $<0.0001$ \\
\hline
\end{tabular}

All values are given as mean + standard deviation (range)

$L A D=$ Left anterior descending coronary artery; LCx = left circumflex coronary artery; RV = right ventricle; $L V=$ left ventricle
2018). Frequency and percentage values were given for categorical variables. Mean, standard deviation, median, minimum, and maximum values were given for continuous variables. Distribution analysis of the continuous variables was performed with the Kolmogorov-Smirnov test. The Mann-Whitney U-test was used for the independent two groups in the variables that did not realize the normal distribution assumption. A $P$ value < 0.05 was considered statistically significant.

\section{Results}

A total of 40 patients undergoing breast-conserving surgery for early stage breast cancer were included in the study. Twenty patients had rightsided breast cancer and 20 had a left-sided one.

In patients with right-sided breast cancer, the median age was 57 years (40-80 years). In 15 of the patients $(75 \%)$, the tumor size was $\leq 2 \mathrm{~cm}$ (T1), and in 5 of them (25\%), it was $2-5 \mathrm{~cm}$ (T2). In 6 of the patients $(30 \%)$, the tumor was in the inner quadrant, and in 14 of them (70\%), in the external quadrant (Table 1). None of the patients had lymph node involvement or distant metastasis. Moreover, 7 of the patients (35\%) received chemotherapy ( 4 cycles in 4 patients, 6 cycles in 3 patients).

In the patients with left-sided breast cancer, the median age was 61 years (42-76 years). In 12 of the patients $(60 \%)$, the tumor size was $\leq 2 \mathrm{~cm}(\mathrm{~T} 1)$, and in 8 of them $(40 \%)$, it was $2-5 \mathrm{~cm}$ (T2). In 10 of the patients (50\%), the tumor was located in the inner quadrant, and in other 10 of them (50\%), in the external quadrant. None of the patients had lymph node involvement or distant metastasis. Moreover, 11 patients (55\%) were treated with chemotherapy (4 cycles in 6 patients and 6 cycles in 5 patients) (Table 1 ).

The doses calculated after RT planning in patients with right- and left sided breast cancer are presented in Table 2. All Dmean, Dmax and Dmin values on LAD, LCx, RV, LV and heart of the patients with left-sided breast cancer were significantly higher than the values of the patients with right-sided cancer $(\mathrm{P}<0.0001)$.

The mean V5 of the LV was $18.68 \%$ (6.89-31.69). It was $10 \%$ or less in 3 patients and high in 17 patients. The mean V25 of the LV was 5.22\% (0.4516.54). The mean V5 in the bilateral ventricles was $23.73 \%$ (2.56-26.89). The mean V25 in the bilateral ventricles was $6.78 \%(0.63-13.63)$. It was $\leq 5 \%$ in 7 patients and $>5 \%$ in 13 patients. 


\section{Discussion}

The most important risk factor for breast cancer development is age. General treatment modalities are surgery (radical mastectomy or breast-sparing surgery or lumpectomy), KT (neoadjuvant or adjuvant) and RT (neoadjuvant or adjuvant). Adjuvant radiotherapy for breast cancer can cause late cardiac complications. Latest update for Early Breast Cancer Trial Writers Cooperation Group demonstrates radiation therapy was associated with excessive cardiac mortality disease. However, many of the studies included in a review involved older treatment techniques, which probably delivered a higher dose to the heart than seen in modern radiotherapy clinics. The issue of cardiac morbidity and mortality after breast cancer treatment is still relevant, as demonstrated by recent publications on the topic. The heart's dose distribution is not homogeneous, and the highest doses are probably to be delivered to the anterior heart which include the LAD. This is a concern since new research suggests that arteries are particularly susceptible to radiation, and LAD is a typical site of origin for ischemic heart disease. ${ }^{8}$ Multiple follow-up studies have shown that delivery of radiation to chest wall or breast results in delayed cardiac morbidities ranging from ischemic heart disease (IHD) to acute coronary syndromes and finally congestive cardiac failure. ${ }^{9}$ In our clinic, we used the regimens that were routinely used in breast cancer patients and determined our cardiac dose rates, according to the dose and plan used for right and left-side breast RT, and tried to evaluate the effect of these doses on coronary disease risk.

Aznar MC et al., in their study, included women in the age ranging from 36 to 76 years, with median age 58.5 years, at the time of treatment. ${ }^{8}$ Chung et al., in their study, included women with a median age of 50 (25-74) years. ${ }^{10}$ In our study, the median age of the patients with right-sided breast cancer was 57 (40-80) years and of those with the left-sided breast cancer was 61 (42-76) years.

Long-term survival-related toxicities have become important to be studied, as long-term survival rates have been achieved by the improvements in diagnosis and treatment of breast cancer. Cardiac toxicity is especially important to be checked in left-sided breast RT. In particular, the LAD receives significant radiation, as it is in or near the target volume. Moreover, studies have claimed the cardiovascular mortality to increase after RT. 5,6 Population-based analyses have proven that highdose exposure to heart results in a cardiac morbid- ity and death ${ }^{11}$, however, no cardiac morbidity was observed if heart exposure was negligible or low for the treatment technique used. ${ }^{12}$ In our study, we postulated that the heart entered into the field of RT due to breast cancer should be examined as well as for the doses taken by the subgroups of heart but the cardiac morbidity or the cardiovascular mortality was not examined since it was not a follow-up study.

According to the Quantitative Analyses of Normal Tissue Effects in the Clinic, National Surgical Adjuvant Breast and Bowel Project, and Radiation Therapy Oncology protocols, the heart mean dose is $<26 \mathrm{~Gy}$, < $4 \mathrm{~Gy}$, and < $32 \mathrm{~Gy}$, respectively. The RACE collaboration reported a doseresponse relationship between the heart disease risk and mean dose to the heart. ${ }^{2}$ Compared with the women with estimated heart doses < $5 \mathrm{~Gy}$, the relative risks of heart disease in women with estimated doses 5 to 14 Gy and > 15 Gy were 15\% and $108 \%$ higher, respectively. Although there was a $4 \%$ increase in the risk for each 1-Gy increase in the estimated average heart dose, it is not clear whether this linear relationship exists after very low cardiac doses. The Danish Breast Cancer Cooperative Group recommends that the volume of heart receiving more than $40 \mathrm{~Gy}$ be kept below $5 \%$, as well as the volume receiving more than 20 Gy be kept under $10 \% .{ }^{13}$ Although it is generally accepted that a dose of $40 \mathrm{~Gy}$ or more of radiation can lead to heart disease, McGale and Darby have shown evidence of an increased risk of radiationinduced heart disease at doses below 5 Gy. ${ }^{14}$ In our study, the mean doses for heart of patients with a left-sided breast cancer was $3.97 \pm 1.32 \mathrm{~Gy}$, and maximum dose was $50.32 \pm 3.31 \mathrm{~Gy}$. For hearts of patients with a right-sided breast cancer, the mean of dose was $1.20 \pm 0.19 \mathrm{~Gy}$, and maximum dose was $6.34 \pm 7.52 \mathrm{~Gy}$, suggesting a reasonable estimated lower dose on heart compared with the heart of patients with left-sided breast cancer for the relative risk of heart.

In one study, clinically significant perfusion defects after RT were not found when the mean heart rate was kept below $<5 \mathrm{~Gy}$, using 3-dimensional conformal radiation therapy (3D-CRT) or intensity-modulated radiation therapy techniques, and precise measurements of cardiac function. In addition, there was no correlation between heart perfusion or function of low doses, according to the dose ratios of the heart. Although the long-term clinical significance of perfusion defects and heart disease is not known, the lack of worsening defects 1 year after a low-dose exposure is encouraging. ${ }^{10}$ As a 
limitation in our study, the long-term effects of RT should be investigated for the perfusion defects and heart disorders in future.

Although the survival advantage provided by adjuvant radiation has been demonstrated ${ }^{15,16}$, the increased rates of cardiac morbidity and mortality have been well described. ${ }^{17-20}$ To adequately predict the cardiac risks of modern radiation techniques, the determination of a relationship between cardiac doses and long-term morbidity and mortality is necessary. Previous reports have attempted to correlate the risk of cardiac injury with doses received by the heart. ${ }^{19,21}$ Hooning et al., retrospectively reviewed the incidence of cardiovascular disease in 10-year survivors of breast cancer, treated from 1970 through $1986 .{ }^{21}$ Although the risk of cardiovascular disease increased with increasing estimated mean heart doses, the risk was decreased with more modern treatment techniques. More recently, Nilsson et al., demonstrated with coronary angiography that the location and severity of coronary artery stenosis correlates with the expected regions of high-dose radiation, especially for leftsided radiation or inclusion of the internal mammary nodes. ${ }^{19}$ Correa et al., conducted a study on 14 patients, 13 with left and one with right-sided breast cancer, who had stress tests and underwent cardiac catheterization. In this study, in 11 of the 13 patients, the LAD was affected. In 8 of these 11 patients, a single vessel was affected, in one patient, both LADs and the LCx were diseased, and in one other patient, three main coronary vessels were diseased. On the other hand, 1 patient had LCx and right coronary stenosis without evidence of LAD disease. ${ }^{22}$ In our study, not only the mean and maximum doses of RT on heart of left-sided breast cancer were higher than the right-sided cancer, but also the mean, maximum and minimum doses on LAD, LCx, and both ventricles of left-sided cancer were also significantly higher than left-sided cancers, suggesting a possibility of tendency for heart diseases as well as LAD and LCx diseases.

Many different RT regimens were used from 1970 to 2000, and it was not possible to calculate the dose of heart and coronary arteries in most patients. Taylor et al. did a study to describe hot-spot areas for radiation and classify RT as high or lowrisk. ${ }^{23}$ In their study, the mean doses received by Swedish women treated for left-sided breast cancer in the 1990s were 3.0 \pm 0.5 Gy to the heart and $12.0 \pm 2.3 \mathrm{~Gy}$ to the LAD (including $1 \mathrm{~cm}$ margin). ${ }^{24}$ Aznar et al. found that the mean doses to cardiac structures were $2.9 \pm 2.2$ Gy to the heart and 17.8 \pm 14 Gy to the whole LAD (f1). ${ }^{8}$ In our study, the mean doses to heart were calculated as $1.20 \pm 0.19$ Gy and $3.97 \pm 1.32$ Gy in the right- and left-sided breast cancer, respectively. Moreover, the mean doses to LAD were calculated as $0.97 \pm 0.10 \mathrm{~Gy}$ and $24.03 \pm 8.38$ Gy in the right- and left-sided breast cancer, respectively. These differences with the literature could be caused by differences in treatment techniques or more likely in contouring strategy: in the present study, the irradiation technique uses tangential fields with CT based planning. These results also indicate that a very low dose to LAD seems to be associated with a very low dose to the heart for breast tumors in different sides. To provide additional information, we suggest that LAD should be contoured as a risk organ along with the whole heart and used prospectively for optimization of RT plan. If it is not possible to contour both structures owing to limited time, the LAD should be preferred as an organ at risk.

In RT to the breast cancer, the anterior part of the heart, including the LAD, receives the highest radiation doses. The LAD dose was generally greater than the dose administered to the whole heart or to the other two coronary arteries. ${ }^{23}$ In another study, for irradiated left- versus right-sided breast cancers, the odds ratio (OR) for grade 3 to 5 stenosis in mid and distal (md) LAD $+\mathrm{dD}$ was 4.38 (95\% confidence interval [CI], 1.64 to 11.7$)$ and for grade 4 to 5 stenosis, the OR was 7.22 (95\% CI, 1.64 to 31.8$)$. For high-risk RT versus low-risk or no RT, the OR for grade 3 to 5 stenosis in hot-spot areas was 1.90 (95\% CI, 1.11 to 3.24). An increase of stenosis in mdLAD + dD in irradiated left-sided breast cancer and an association between high-risk RT and stenosis in hot-spot areas for radiation indicate a direct link between radiation and location of coronary stenosis. ${ }^{19}$ In our study, the highest radiation dose in patients with left-sided breast cancer was to LAD (mean $24.03 \pm 8.39 \mathrm{~Gy}$ ), while in rightsided breast cancer patients, it was to the RV (mean $1.30 \pm 0.25 \mathrm{~Gy}$ ), suggesting that it is not sufficient to calculate the dose to one organ as an estimate of the dose to all cardiac structures, and recommending that both ventricles and the LAD be contoured and their respective dose burdens be considered in RT of breast.

Handbook recommendation for breast RT is as follows: LV and combined bilateral ventricle limits: V5 $\leq 10 \%$ and V25 $\leq 5 \%$. The American Society for Radiation Oncology (ASTRO) Consensus Statement dose constraints for 3D-CRT Accelerated Partial Breast Irradiation (IJROBP 2009) reports as follows: heart V5 $<5 \%$ for right-sided tumors and $<40 \%$ for left-sided tumors. ${ }^{25}$ In our study, the 
mean V5 of the LV was $18.68 \%$, and $10 \%$ or less in 3 patients and higher in 17 patients compared with the recommendation of ASTRO Consensus Statement. However, the mean V25 of the LV was $5.22 \%$ and consistent with the recommendations. The mean V5 in the bilateral ventricles was $23.73 \%$ (2.56-26.89). The mean V25 in the bilateral ventricles was $6.78 \%$, and $\leq 5 \%$ in 7 patients and $>5 \%$ in 13 patients. These limits are also higher for more patients than the recommendations, suggesting that might be linked to an increased risk of cardiac complications which has not been taken into account in the current study.

According to the guidelines, to minimize cardiac side effects, the left ventricular dose should be $\mathrm{V} 5 \leq 10 \%$, the bilateral ventricular dose V25 $\leq$ $5 \%$, and the whole heart dose $<4 \mathrm{~Gy}$. For this purpose, in a dosimetric analysis, free and breath hold technique were planned with both forward and inverse IMRT presenting a significant decrease of radiation exposure to the contralateral breast, left and RVs, as well as proximal and especially distal LAD by breath hold with forward IMRT. ${ }^{26}$ Another study reported that deep inspiration breath hold plans proved large reductions of dose to the heart. V20 of the heart is reduced from $7.8 \%$ to $2.3 \%$, V 40 from $3.4 \%$ to $0.3 \%$ and mean dose from 5.2 to 2.7 Gy. ${ }^{27}$ This may be another goal of future studies to reduce the risks of heart diseases in $\mathrm{RT}$ of breast cancer.

During the past few decades, the wide variation in the cardiac doses worldwide are likely to have resulted from the diversity in RT practice. Our estimates including coronary artery and heart doses in right and left-sided breast cancers will be useful when deriving dose-response relationships. These results emphasize the importance of using treatment techniques in the left-sided breast cancer that minimize cardiac irradiation, consistent with the "as low as reasonably achievable" concept, and the need for further study of the long-term clinical impact after low-dose exposure.

\section{Conclusions}

Almost all patients with breast cancers are exposed to cardiotoxic chemotherapy and potentially cardiotoxic RT to the heart vessels. In the background of modern techniques, especially in left-sided breast cancer, the most direct and best strategy to reduce and protect radiation-induced cardiac injury is to balance dose constraints between several highdose regions of cardiac substructures and the mean heart dose. If necessary, deep inspiration breath hold respiratory gating, prone positioning or MLC blocking may be used to minimize dose to heart. Additional work is needed to better understand the dose/volume/effect relationships for cardiac injury, and to find authoritative approaches, which can be the guidelines for detection and management of radiation-related heart diseases.

\section{References}

1. Ferlay J, Shin HR, Bray F, Forman D, Mathers C, Parkin DM. Estimates of worldwide burden of cancer in 2008: Globocan 2008. Int J Cancer 2010; 127: 2893-917. doi: 10.1002/ijc.25516

2. Recht A, Edge SB, Solin $\amalg$, Robinson DS, Estabrook A, Fine RE, et al. Postmastectomy radiotherapy: guidelines of the American Society of Clinical Oncology. J Clin Oncol 2001; 19: 1539-69. doi: 10.1200/JCO.2001.19.5.1539

3. Cuzick J, Stewart H, Rutqvist L, Houghton J, Edwards R, Redmond C, et al. Cause-specific mortality in long-term survivors of breast cancer who participated in trials of radiotherapy. J Clin Oncol 1994; 12: 447-53. doi: 10.1200/ JCO.1994.12.3.447

4. Overgaard M, Jensen MB, Overgaard J, Hansen PS, Rose C, Andersson M, et al. Postoperative radiotherapy in high-risk postmenopausal breast cancer patients given adjuvant tamoxifen: Danish Breast Cancer Cooperative Group DBCG 82c randomised trial. Lancet 1999; 353: 1641-8. doi: 10.1016/ S0140-6736(98)09201-0

5. Rutqvist LE, Lax I, Fornander T, Johansson H. Cardiovascular mortality in a randomized trial of adjuvant radiation therapy versus surgery alone in primary breast cancer. Int J Radiat Oncol Biol Phys 1992; 22: 887-96. doi: 10.1016/0360-3016(92)90784-f

6. Taylor CW, McGale P, Darby SC. Cardiac risks of breast cancer radiotherapy: A contemporary view. Clin Oncol 2006; 18: 236-46. doi: 10.1016/j. clon.2005.11.003

7. McGale P, Darby SC, Hall P, Adolfsson J, Bengtsson NO, Bennet AM, et al. Incidence of heart disease in 35,000 women treated with radiotherapy for breast cancer in Denmark and Sweden. Radiother Oncol 2011; 100: 167-75. doi: 10.1016/j.radonc.2011.06.016

8. Aznar MC, Korreman SS, Pedersen AN, Persson GF, Josipovic M, Specht L. Evaluation of dose to cardiac structures during breast irradiation. BrJ Radiol 2011; 84: 743-6. doi: 10.1259/bjr/12497075

9. Roy S, Mondal D, Melgandi W, Jana M, Chowdhury KK, Das S, et al. Impact of post-operative radiation on coronary arteries in patients of early breast cancer: A pilot dosimetric study from a tertiary cancer care center from India. Indian J Cancer 2015; 52: 114-7. doi: 10.4103/0019-509X.175562

10. Chung E, Corbett JR, Moran JM, Griffith KA, Marsh RB, Feng M, et al. Is there a dose-response relationship for heart disease with low-dose radiation therapy? Int J Radiat Oncol Biol Phys 2013; 85: 959-64. doi: 10.1016/j. ijrobp.2012.08.002

11. Henson KE, McGale P, Taylor C, Darby SC. Radiation-related mortality from heart disease and lung cancer more than 20 years after radiotherapy for breast cancer. Br J Cancer 2013; 108: 179-82. doi: 10.1038/bjc.2012.575

12. Højris I, Overgaard M, Christensen JJ, Overgaard J. Morbidity and mortality of ischaemic heart disease in high-risk breast-cancer patients after adjuvant postmastectomy systemic treatment with or without radiotherapy: analysis of DBCG $82 \mathrm{~b}$ and $82 \mathrm{c}$ randomised trials. Radiotherapy Committee of the Danish Breast Cancer Cooperative Group. Lancet 1999; 354: 1425-30. doi: 10.1016/s0140-6736(99)02245-x

13. Christiansen P, Ejlertsen B, Jensen MB, Mouridsen H. Danish Breast Cancer Cooperative Group. Clin Epidemiol 2016; 8: 445-9. doi: 10.2147/CLEP. S99457

14. McGale P, Darby SC. Low doses of ionizing radiation and circulatory diseases: a systematic review of the published epidemiological evidence. Radiat Res 2005; 163: 247-57. doi: 10.1667/rr3314 
15. Clarke M, Collins R, Darby S, Davies C, Elphinstone P, Evans V, et al. Effects of radiotherapy and of differences in the extent of surgery for early breast cancer on local recurrence and 15-year survival: an overview of the randomised trials. Lancet 2005; 366: 2087-106. doi: 10.1016/S0140-6736(05)67887-7

16. Darby S, McGale P, Correa C, Taylor C, Arriagada R, Clarke M, et al. Effect of radiotherapy after breast conserving surgery on 10-year recurrence and 15-year breast cancer death: Meta-analysis of individual patient data for 10,801 women in 17 randomised trials. Lancet 2011; 378: 1707-16. doi: $10.1016 /$ S0140-6736(11)61629-2

17. Darby SC, McGale P, Taylor CW, Peto R. Long-term mortality from heart disease and lung cancer after radiotherapy for early breast cancer: Prospective cohort study of about 300,000 women in US SEER cancer registries. Lancet Oncol 2005; 6: 557-65. doi: 10.1016/S1470-2045(05)70251-5

18. Jagsi R, Griffith KA, Koelling T, Roberts R, Pierce $\amalg$. Rates of myocardial infarction and coronary artery disease and risk factors in patients treated with radiation therapy for early-stage breast cancer. Cancer 2007; 109: 6507. doi: 10.1002/cncr.22452

19. Nilsson G, Holmberg L, Garmo H, Duvernoy O, Sjögren I, Lagerqvist B, et al. Distribution of coronary artery stenosis after radiation for breast cancer. $J$ Clin Oncol 2012; 30: 380-6. doi: 10.1200/JCO.2011.34.5900

20. Paszat LF, Vallis KA, Benk VM, Groome PA, Mackillop WJ, Wielgosz A. A population-based case-cohort study of the risk of myocardial infarction following radiation therapy for breast cancer. Radiother Oncol 2007; 82: 294-300. doi: 10.1016/j.radonc.2007.01.004

21. Hooning MJ, Botma A, Aleman BM, Baaijens MH, Bartelink H, Klijn JG, et al. Long-term risk of cardiovascular disease in 10-year survivors of breast cancer. J Nat/ Cancer Inst 2007; 99: 365-75. doi: 10.1093/jnci/djk064

22. Correa CR, Litt HI, Hwang WT, Ferrari VA, Solin L, Harris EE. Coronary artery findings after left-sided compared with right-sided radiation treatment for early-stage breast cancer. J Clin Oncol 2007; 25: 3031-7. doi: 10.1200/ JCO.2006.08.6595

23. Taylor CW, Nisbet A, McGale P, Darby SC. Cardiac exposures in breast cance radiotherapy: 1950s-1990s. Int J Radiat Oncol Biol Phys 2007; 69: 1484-95. 24. doi: 10.1016/j.ijrobp.2007.05.034

24. Taylor CW, Nisbet A, McGale P, Goldman U, Darby SC, Hall P, et al. Cardiac doses Cardiac exposures in breast cancer radiotherapy: 1950s-1990s.from Swedish breast cancer radiotherapy since the 1950s. Radiother Oncol 2009; 90: 127-35. doi: 10.1016/j.radonc.2008.09.029

25. Smith BD, Arthur DW, Buchholz TA, Haffty BG, Hahn CA, Hardenbergh PH, et al. Accelerated partial breast irradiation consensus statement from the American Society for Radiation Oncology (ASTRO). Int J Radiat Oncol Biol Phys 2009; 74: 987-1001. doi: 10.1016/j.jirobp.2009.02.031

26. Bolukbasi Y, Saglam Y, Selek U, Topkan E, Kataria A, Unal Z, et al. Reproducible deep-inspiration breath-hold irradiation with forward intensity-modulated radiotherapy for left-sided breast cancer significantly reduces cardiac radiation exposure compared to inverse intensity-modulated radiotherapy. Tumori 2014; 100: 169-78. doi: 10.1700/1491.16405

27. Nissen HD, Appelt AL. Improved heart, lung and target dose with deep inspiration breath hold in a large clinical series of breast cancer patients. Radiother Oncol 2013; 106: 28-32. doi: 10.1016/j.radonc.2012.10.016 